\title{
Assessing health-related quality-of-life changes in informal caregivers: an evaluation in parents of children with major congenital anomalies
}

\author{
Marten J. Poley • Werner B. F. Brouwer • \\ N. Job A. van Exel · Dick Tibboel
}

Accepted: 4 August 2011

(C) The Author(s) 2011. This article is published with open access at Springerlink.com

\begin{abstract}
Purpose Relatively few attempts to measure the effects on the health-related quality of life (HRQoL) of informal caregivers within the context of economic evaluations have been reported. This paper is an exploratory attempt to find suitable methods to assess caregivers' HRQoL, using a population of parents of children with major congenital anomalies.

Methods A total of 306 parents of children born with either congenital anorectal malformations (ARM) or congenital diaphragmatic hernia were surveyed. They rated their current HRQoL on the EQ-VAS. After that, they rated their HRQoL again on the assumption that someone would take over their caregiving activities completely and free of charge. Finally, the parents classified their HRQoL on the EQ-5D. The caregivers' scores on the EQ-VAS and the EQ-5D were compared with scores elicited in the general population.

Results Most parents indicated that their HRQoL would not change if someone else took on their caregiving activities. Some methodological issues may have influenced this outcome, such as difficulties in self-assessing HRQoL changes due to caregiving, process utility, protest answers, and difficulties in understanding the hypothetical question. The HRQoL of the parents was relatively low compared with population statistics, especially in the parents of children with ARM and in mothers. This can be
\end{abstract}

M. J. Poley $(\bowtie) \cdot$ D. Tibboel

Department of Pediatric Surgery, Sophia Children's Hospital,

Erasmus MC, P.O. Box 2060, 3000 CB Rotterdam,

The Netherlands

e-mail: poley@bmg.eur.nl

M. J. Poley · W. B. F. Brouwer · N. J. A. van Exel Institute for Medical Technology Assessment (iMTA), Erasmus University Rotterdam, Rotterdam, The Netherlands illustrated by the difference between the mean EQ-5D score of the mothers aged 25-34 years of the children with ARM and that of the general population $(0.83$ vs. 0.93 ; $P=0.002$ ).

Conclusions Significant HRQoL differences exist between parents caring for children with congenital anomalies and the general population. It would be useful to further improve our understanding of the HRQoL impact of informal caregiving, separating 'caregiving effects' from 'family effects', and distinguishing parent-child relationships from other caregiving situations. This study underlines the importance of considering caregivers, also in the context of economic evaluations. It indicates that general HRQoL measures, as used in patients, may be able to detect HRQoL effects in caregivers, which facilitates the incorporation in common economic evaluations of HRQoL effects in carers. Analysts and policy makers should be aware that if HRQoL improvement is an important aim, they should register HRQoL changes not only in patients but also in their caregivers.

Keywords Economic evaluation - Valuation of informal care $\cdot$ Methodology $\cdot$ Quality of life · Neonatal surgery
Abbreviations
ARM Congenital anorectal malformations
$\mathrm{CDH} \quad$ Congenital diaphragmatic hernia
HRQoL Health-related quality of life

\section{Introduction}

Defined as 'the comparative analysis of alternative courses of action in terms of both their costs and consequences' [1], economic evaluations have become an important tool to 
inform decision makers about both the costs and effects of health care technologies. It is typically recommended to adopt a comprehensive societal perspective in these evaluations $[1,2]$. This implies that all costs and effects should be taken into account, regardless of who experiences them. As several authors have pointed out, this means that both the costs and effects experienced by significant others, such as informal caregivers, should be incorporated in economic evaluations [2, 3]. Even in jurisdictions where a more restrictive health care perspective is adopted, such as England and Wales, it has been argued that it would be appropriate to at least incorporate health effects in carers in these evaluations [4].

In recent years, much progress has been made regarding how to value the costs of informal care, even though several controversial issues remain, for example regarding how to measure the time spent on informal care (separating it from time spent on other activities) and how exactly to attach a monetary value to the time inputs by caregivers $[5,6]$. In this paper, we concentrate on measuring the health-related quality-of-life (HRQoL) effects in informal caregivers. Measuring such effects could be used to complement methods that measure and value the costs of informal care (without simultaneously valuing effects) in order to include the full impact of informal care in economic evaluations.

In the literature, a distinction has been made between 'family effects' and 'caregiving effects' [3, 7-10]. The former refers to the effects (on HRQoL, or another outcome measure) of the fact that someone within the caregiver's social environment is ill. These effects are not specifically related to caregiving: they may also exist when no caregiving tasks have to be performed and may therefore occur in a broader group than caregivers only. The latter relates to the effects of performing caregiving tasks. By definition, these effects are only present in informal caregivers. Of note, depending on the context, these two types of effects may both occur in informal caregivers, since caregivers are often family members of patients.

Effects in caregivers can be assessed not only in terms of HRQoL changes but also in terms of burden or well-being $[8,9]$. Indeed, there has been extensive investigation of the objective and subjective burden of informal care [11-13]. Yet, such burden assessments in itself do not comprise a valuation of some type, and therefore, they are not directly useful for economic evaluations. Also, it is likely that the caregivers' general well-being, in a broad sense, may be affected, given that caregiving may involve different implications such as having to perform unpleasant tasks, interruption of daily activities, social isolation, and adverse financial consequences. Methods to measure and value the general well-being effects on caregivers have been developed $[14,15]$. However, the incorporation of such effects in economic evaluations may be difficult for two reasons. First, in jurisdictions where a strict health care perspective is prescribed, effects on well-being may be considered beyond the scope of the analysis. Second, since 'even' in patients usually only effects on HRQoL-which refers to the aspects of quality of life that relate specifically to a person's health-are measured, measuring broader effects in caregivers may be considered inconsistent and may be practically difficult (creating the problem of how to combine two distinct outcome measures) [3].

Therefore, a first step to include the effects on informal caregivers in economic evaluations may be to measure HRQoL changes as a result of caregiving. It has been documented before that caregiving has health effects for the caregivers, both physically and mentally [16-18]. HRQoL effects may be measured by using instruments similar to the ones used to assess patients' HRQoL and could, in principle, be easily combined with outcomes of patients' HRQoL in economic evaluations. Such HRQoL effects in carers are not only relevant when adopting a societal perspective but also when taking a more narrow health care perspective. Note again that these effects in caregivers may comprise both the caregiving and the family effect (raising the obvious question of whether HRQoL effects in non-caregiving family members should also be measured).

Still, until now, relatively few attempts to measure HRQoL effects in carers within the context of economic evaluations have been reported. To give some examples, Mohide et al. used the time trade-off technique to assess HRQoL of caregivers. The authors found this method, normally used to assess patient's HRQoL, to be feasible, reliable, and valid [19]. Dixon and colleagues carried out a study into the relationships between patient HRQoL, carer HRQoL, and time spent on caring. They concluded that improving patient HRQoL may reduce the need for carer time and improve carer HRQoL [20]. Davidson et al. tried to capture the effects of caring for older people by adjusting the carers' QALY weights. They found that caring for a relative had a negative effect on these QALY weights [21]. Drawing on a theoretical framework for incorporating the effects of patients' health on their family members [7], Basu et al. applied a time trade-off technique to elicit HRQoL weights of partners of patients with prostate cancer. There appeared to be a significant effect of the patient's health condition on the partner's HRQoL [22]. Finally, Bobinac et al. studied the effects of caregiving on well-being or HRQoL in a large sample of Dutch caregivers and tried to separate family effects and caregiving effects [8, 9].

In conclusion, the HRQoL of caregivers is likely to change due to caregiving and family effects, and it is worthwhile to further develop valid and practical methods 
to measure this change in the context of economic evaluations. With this in mind, we set up a study in a group of informal caregivers consisting of parents of children with major congenital anomalies. Several studies-albeit not within the context of economic evaluations-revealed that parents of children with congenital and/or chronic conditions have a relatively low HRQoL [23-26]. Our study aimed to identify what these parents of children with major congenital anomalies do for their children and what effects caregiving has on their HRQoL and to compare their HRQoL with that of the general population. The underlying aim was to find, in an exploratory way, suitable methods to assess informal caregivers' HRQoL, to be applied in economic evaluations.

\section{Materials and methods}

\section{Setting}

The study was performed in a population of informal caregivers approached in the context of an economic evaluation of neonatal surgery [27, 28]. The population comprised parent-caregiver(s) of children that were born with a major congenital anomaly and who had received neonatal surgery in the Sophia Children's Hospital (Rotterdam, The Netherlands). We included the parents of patients that were between 1 and 11 years of age. Parents whose child had died were excluded. Data were collected by means of a postal questionnaire, which included questions on the demographics of the child and his or her parent(s) and on the child's condition. Two copies were enclosed for the parent(s) of each patient and, where relevant, both parents were asked to fill in the questionnaire. From the medical files of the patients, we retrieved information such as underlying diagnosis, operations, and length of stay. Ethical approval by our Institutional Review Board was not required, because the study concerned the collection and analysis of data arising from standard care in our department (the participants not being subjected to any acts or being enforced any behaviors outside the realm of standard care). Informed consent was obtained from all parents.

Children eligible to participate were born with either congenital anorectal malformations (ARM) or congenital diaphragmatic hernia $(\mathrm{CDH})$. The former are complex anomalies (ranging from a slight malposition or stenosis of the anus to the absence of an anal opening in the perineum) with a high incidence of associated urological problems, but the malformations are not life threatening as a rule. The HRQoL of patients with ARM however is a subject of concern [29-33]. CDH consists of a combination of pulmonary hypoplasia, abnormal pulmonary vascular growth, and a defect of the diaphragm that allows abdominal viscera to move up into the chest cavity. Despite the many advances in medical therapy and although better survival rates have been published [34, 35], the mortality rate in $\mathrm{CDH}$ still remains around $20-40 \%$. In the survivors, a variety of symptoms has been reported especially in the first years of life [36-38], but eventually most CDH survivors enjoy healthy lives [39-41]. Thus, ARM is characterized by relatively high morbidity and relatively low mortality, whereas for $\mathrm{CDH}$, the opposite applies. We used this contrast in this study. Generally, caregiving for patients with ARM is expected to take more time and to be more discomforting than that for patients with $\mathrm{CDH}$. Presumably, parents of patients with ARM have to perform heavier and more skilled care tasks (e.g., dealing with a colostomy) for patients with more and longer-lasting physical dysfunction such as incontinence. The relative sizes of family effects are more difficult to predict.

\section{Design}

The study was designed to provide different types of information on the informal caregivers' (that is: the parents') HRQoL. As will be explained below, the HRQoL effects in caregivers were investigated in two ways: (1) hypothetical HRQoL effects and (2) real HRQoL effects. Next to this, to get an impression of the objective burden of caregiving, caregiving activities and foregone paid work and unpaid activities were studied.

\section{Caregiving and foregone activities}

We investigated whether or not it was the parents' impression that their child demanded above-average care and, if so, using an open-ended question, what activities were involved. The parents were questioned about the amount of extra hours spent per week on caregiving compared with other children of the same age. Moreover, we studied whether the parents, in order to provide informal care, had to forgo paid work and unpaid activities (i.e., household work, shopping, odd jobs, club activities and volunteer work, education, and sleep), expressed as number of hours per week.

\section{HRQoL effects}

Caregivers were first asked to rate their current HRQoL on the EQ-VAS, a $20-\mathrm{cm}$ visual analog scale (similar to a thermometer) ranging from 0 (worst imaginable health state) to 100 (best imaginable health state) [42]. This provides information on their self-assessed quality of life and can be compared to ratings of the general population [43]. Second, caregivers were asked to rate their HRQoL 
again on the assumption that someone would take over their caregiving activities completely and free of charge, so that they will no longer have to spend time on their current caregiving tasks. Third, caregivers were asked to classify their HRQoL on the EQ-5D descriptive system [42]. This involved responders classifying themselves on five dimensions of HRQoL, which together encompass both physical, psychological, and social HRQoL: mobility, selfcare, usual activities, pain/discomfort, and anxiety/depression. Each dimension is subdivided into three levels of dysfunction, which correspond to whether a responder has no problems, some or moderate problems, or extreme problems. Accordingly, this 'descriptive system' generates $243\left(3^{5}\right)$ theoretically possible health states. Dolan was the first to publish a value set for all these health states. Health states are then commonly assigned a weight between 1 (perfect health) and 0 (dead), with certain poor health states receiving negative weights (i.e., worse than dead) [44]. As with the EQ-VAS scores, the EQ-5D scores of informal caregivers can be compared with reference scores [43]. The minimally important difference-which is the smallest, yet important or meaningful difference or change in a HRQoL score-for both the EQ-VAS and EQ-5D is considered to be roughly around 5\% (that is, five points on the 0-100 EQVAS scale and 0.05 on the $0-1$ EQ-5D scale) [45-47]. Both the EQ-VAS and the EQ-5D descriptive system were developed by the EuroQol Group. More details on both instruments are available through http://www.euroqol.org.

In theory, the HRQoL change due to caregiving specifically, excluding 'family effects', can be determined by looking at the difference between the two scores on the EQ-VAS. After all, in the hypothetical scenario in which someone else would take over all caregiving tasks, the family effect is still present, as the patient's health is not assumed to improve. We aimed at deriving the effect of caregiving on HRQoL directly by asking about this hypothetical scenario, but were unsure whether responders could provide a valid assessment of this effect. Therefore, we also used the comparison of the caregivers' scores on the EQ-VAS and the EQ-5D with scores elicited in the general population as validation checks and as a possible alternative way of deriving HRQoL changes in caregivers. These differences with general population scores would relate both to caregiving and to the effect of having an ill child (the family effect).

\section{Statistical analyses}

The analyses were stratified by parent (mother/father). Differences between the two scores on the EQ-VAS (i.e., the actual current HRQoL and the HRQoL in the hypothetical scenario) were tested using paired-samples $t$ test. One-way analysis of variance (ANOVA) with Bonferroni post hoc tests (for continuous variables) or chi-square test (for categorical variables) were applied to compare subgroups of parents who claimed that their HRQoL would either increase, decrease, or be the same in the hypothetical scenario in which care tasks would be taken over. We hypothesized that the parents who indicated that their HRQoL would improve in the scenario in which care tasks would be taken over (compared with those indicating that their HRQoL would not differ or would even diminish) were more likely to:

1. Be parents of ARM patients (rather than of $\mathrm{CDH}$ patients);

2. Be female;

3. Take care of a young child;

4. Take care of the child alone;

5. Have given up paid work;

6. Report a shortage of time for more unpaid activities;

7. Have a lower monthly gross income;

8. Take care of a child with a relatively low HRQoL according to the symptom score and the EQ-VAS;

9. Have a relatively low HRQoL (as expressed by the EQ-VAS scores and the EQ-5D scores compared to the reference scores).

One-sample $t$ test was used to test for differences in means between the parents' EQ-VAS and EQ-ED scores and those of the general population.

In addition, we wondered whether it would be possible to explain differences between the parents' HRQoL and the age- and sex-specific HRQoL scores of the general population. Both the differences on the EQ-VAS and on the EQ5D were taken as dependent variables in a standard linear regression model. For further explanatory purposes, we selected only those independent variables that were considered most important. Moreover, in order to avoid multicollinearity, predictors of HRQoL that correlated highly with other predictors were not selected. The independent variables were as follows:

1. Congenital anomaly (i.e., ARM or $\mathrm{CDH}$ );

2. The child's age;

3. Symptom score of the ARM patients;

4. Symptom score of the CDH patients;

5. Taking care of the child alone or with a partner;

6. (Not) having given up paid work as a particular consequence of the anomaly;

7. Number of unpaid activities the parent can spend less time on (ranging from zero to six);

8. Monthly gross income;

9. The child's HRQoL as assessed by the parent on the EQ-VAS.

Adjusted R Square was calculated as a measure of the goodness-of-fit of the model. 
Table 1 Demographic characteristics of the patients and their parents

\begin{tabular}{lll}
\hline Patients characteristics & ARM & CDH \\
\hline Number & 118 & 46 \\
Mean age (SD) & $6.1(3.0)$ & $6.0(3.1)$ \\
Sex (\% female) & $42 \%$ & $48 \%$ \\
Number of parents (\%) & & \\
$1^{\mathrm{b}}$ & $12(10 \%)$ & $6(13 \%)$ \\
$2^{\mathrm{c}}$ & $104(88 \%)$ & $40(87 \%)$ \\
\hline Parents characteristics & Female & Male \\
\hline Number of parents & 161 & 145 \\
Mean age (range) & $35(22-48)$ & $38(24-59)$ \\
Total number of children in household & 2.2 & 2.4 \\
Caregiving together with a & $89 \%$ & $99 \%$ \\
partner (thus, not alone) $(\%)$ & &
\end{tabular}

${ }^{a}$ For 2 patients with ARM, we have no data on informal caregiving, as the section of the questionnaires concerning caregiving was skipped

b When only one parent filled in the questionnaire, mostly (94\% of all cases) this was a female

c When two parents filled in the questionnaires, mostly (99\% of all cases) these were a female and a male

Next to that, the following two hypotheses were tested. First, we anticipated that the model would have more exploratory power for female caregivers compared to males, because female caregivers are likely to spend more time on caregiving tasks (and thus more likely to have to give up other activities) and therefore may experience HRQoL problems related to caregiving sooner. Second, it was hypothesized that our model would fit better in the explanation of the differences with the general population on the EQ-VAS than the EQ-5D descriptive system. This is because the EQ-VAS might be expected to be more sensitive to small differences as it comprises a continuous scale rather than three distinct levels of functioning per dimension. The EQ-VAS might also be more responsive to changes in emotional HRQoL, which may be especially affected by caring for a child with health problems.

Results were considered statistically significant if they were below the 0.05 level of probability.

\section{Results}

Characteristics of the study population

Of the 198 patients with ARM, 18 died and 14 could not be traced. We also excluded 1 severely cognitively disabled patient. Thus, the parents of 165 patients were sent questionnaires. The response rate was $72 \%(n=118)$. Of the
122 patients with $\mathrm{CDH}$, we had to exclude 45 patients who died and 4 who could not be traced. The parents of the remaining 73 patients were sent questionnaires. Questionnaires were returned by 63\% $(n=46)$. Demographic details of the patients $(n=164$, both diagnostic groups taken together) and their parents $(n=306)$ are listed in Table 1.

Caregiving and forgone activities

Concerning the ARM patients, $48 \%$ of the mothers and $32 \%$ of the fathers had the impression that caregiving for their child required more time than that for other children of similar age. As hypothesized, these percentages are larger than those found in the parents of $\mathrm{CDH}$ patients (24 and $13 \%$, respectively). In patients with ARM, the parents' activities consisted of, for example, giving enemas and changing diapers or underwear, while the parents of $\mathrm{CDH}$ patients mentioned activities such as administering medication or the provision of oxygen (Table 2). If we only take into consideration the parents that had the impression that caregiving for their child required more time than that for other children, the amount of extra hours spent per week on caregiving was 7 in mothers of ARM patients, $5 \mathrm{~h}$ in fathers of ARM patients, and $7 \mathrm{~h}$ in both mothers and fathers of $\mathrm{CDH}$ patients.

Almost half of the mothers had given up paid work for taking care of their child (Table 3). However, these parents might have given up paid work anyway upon their child's birth, regardless of the congenital anomaly. Indeed, only a small proportion of the mothers indicated that they had given up paid work as a particular consequence of the caregiving associated with the anomaly. In fathers, these

Table 2 Most frequent caregiving tasks (top five)

\begin{tabular}{ll}
\hline & $\begin{array}{l}\text { Parents } \\
\text { mentioning } \\
\text { this task }^{\mathrm{a}} \text { (\%) }\end{array}$ \\
\hline Parents of patients with ARM & 58 \\
Giving enemas/lavage & 25 \\
Changing diapers or underwear/washing child & 20 \\
Supervision/extra attention in general/cheering up & 18 \\
Washing (textiles) & 15 \\
Taking care of the child's stoma & \\
Parents of patients with CDH & 44 \\
Supervision/extra attention in general/cheering up & 25 \\
Administering medication & 25 \\
Monitoring oxygen need/provision of oxygen & 25 \\
Preparing special meals/helping with eating & 19 \\
Visiting health care providers & 25 \\
\hline
\end{tabular}

${ }^{a}$ Proportion of all parents who reported that the time for taking care of their child was above average 
Table 3 Forgone Paid Work and Unpaid Activities

\begin{tabular}{|c|c|c|c|c|}
\hline & \multicolumn{2}{|c|}{$\begin{array}{l}\text { ARM patients' } \\
\text { parents }(\%)\end{array}$} & \multicolumn{2}{|c|}{$\begin{array}{l}\text { CDH patients' } \\
\text { parents }(\%)\end{array}$} \\
\hline & Mothers & Fathers & Mothers & Fathers \\
\hline $\begin{array}{l}\text { Parents who gave up paid work for taking } \\
\text { care of their child }\end{array}$ & 46 & 2 & 48 & 7 \\
\hline $\begin{array}{l}\text { Parents who gave up paid work for taking care } \\
\text { of their child as a consequence of the anomaly }\end{array}$ & 12 & 1 & 7 & 0 \\
\hline \multicolumn{5}{|l|}{$\begin{array}{l}\text { Parents indicating that they can spend less time } \\
\text { on unpaid activities: }\end{array}$} \\
\hline Household work & 8 & 3 & 7 & 3 \\
\hline Shopping & 7 & 2 & 7 & 3 \\
\hline Odd jobs & 8 & 10 & 7 & 8 \\
\hline Club activities and volunteer work & 7 & 4 & 5 & 3 \\
\hline Education & 5 & 2 & 7 & 8 \\
\hline Sleep & 12 & 8 & 14 & 11 \\
\hline
\end{tabular}

percentages were substantially lower. As a result, the net labor participation of all mothers that have a partner and whose youngest child is aged $0-4$ years $(n=83)$, for example, was lower than that of their counterparts in the general population [48] (37\% vs. 45\%). Note however that the difference was not statistically significant $(P=0.16)$, so that this finding could be due to chance. The parents also indicated whether they had spent less time on unpaid activities than they wished because of the child's anomaly (Table 3). Parents of ARM patients and those of $\mathrm{CDH}$ patients appeared not to differ very much. Generally, fathers less often reported a shortage of time.

Health-related quality of life

\section{$E Q-V A S$ scores in the real and hypothetical scenarios}

Contrary to our expectations, it emerged that for the majority $(76 \%)$ of parents, the hypothetical scenario did not produce different $\mathrm{HRQOL}$ states from the actual current HRQoL state as indicated on the EQ-VAS. Surprisingly, 9\% of all parents indicated that their HRQoL would in fact diminish in the hypothetical scenario (Table 4). Mean EQVAS scores for both scenarios are also listed in Table 4. No statistically significant differences were found in these means of both EQ-VAS scores, neither in the four subgroups nor in the entire sample.

While the hypothetical score appeared not to differ significantly from the current HRQoL as indicated on the EQ-VAS, this appeared not to be the case for some subgroups (Table 5). To examine the hypotheses mentioned above, the 294 parents who provided an answer to both scenarios were divided into three groups: 47 parents reported hypothetical scores greater than current scores (the difference averaging 11 points), while 222 parents reported no difference, and 25 parents reported hypothetical scores lower than current scores (the difference averaging 27 points). Generally, mothers, parents that had to forgo paid work or unpaid activities, parents of children suffering many symptoms and with a relatively low HRQoL (as reported by the parents), and parents with a relatively low HRQoL themselves (according to the EQVAS) were over-represented in the subgroup of people who claimed that their HRQoL would increase in the hypothetical scenario in which care tasks would be taken over. For example, as can be seen in Table 5, of all parents who reported an increase in the hypothetical scenario $68 \%$ were mothers, as against $49 \%$ of the parents who reported no difference, and $60 \%$ of the parents who reported a decrease in the hypothetical scenario.

\section{$E Q-V A S$ and $E Q-5 D$ compared with the general population}

We compared the parents' EQ-VAS and EQ-5D scores with those of the general population for two age classes of the parents of both patient groups (Table 6). With the exception of the fathers aged between 25 and 34, the EQVAS scores of the parents of the ARM patients were statistically significantly lower than those of the general population. The HRQoL of the $\mathrm{CDH}$ patients' parents, by contrast, did not differ statistically significantly. Using the EQ-5D, the mothers' HRQoL scores turned out to be relatively low. However, by conventional statistical criteria, this difference was significant only for the mothers of ARM patients between 25 and 34 years of age (0.83 vs. 0.93 in the general population; $P=0.002$ ).

Even though the majority of the parents said that their HRQoL would not be different in the hypothetical scenario (Table 4), the analyses showed that differences in means existed between the HRQoL of the parents and the general population (Table 6). By doing a regression analysis, we have tried to explain the parents' relatively low HRQoL 
Table 4 EQ-VAS scores in the real and hypothetical scenarios

\begin{tabular}{|c|c|c|c|c|c|}
\hline & \multicolumn{2}{|c|}{ Parents of patients with ARM $(n)$} & \multicolumn{2}{|c|}{ Parents of patients with $\mathrm{CDH}(n)$} & \multirow[t]{2}{*}{ All parents $(n)$} \\
\hline & Mothers & Fathers & Mothers & Fathers & \\
\hline $\begin{array}{c}\text { EQ-VAS }_{\text {hypothetical }}> \\
\text { EQ-VAS }_{\text {real }}\end{array}$ & $24 \%(26)$ & $11 \%(11)$ & $13 \%(6)$ & $10 \%(4)$ & $16 \%(47)$ \\
\hline $\begin{array}{l}\text { EQ-VAS }_{\text {hypothetical }}= \\
\text { EQ-VAS }_{\text {real }}\end{array}$ & $64 \%(70)$ & $82 \%(80)$ & $84 \%(38)$ & $83 \%(34)$ & $76 \%(222)$ \\
\hline $\begin{array}{c}\text { EQ-VAS }_{\text {hypothetical }}< \\
\text { EQ-VAS }_{\text {real }}\end{array}$ & $13 \%(14)$ & $7 \%(7)$ & $2 \%(1)$ & $7 \%(3)$ & $9 \%(25)$ \\
\hline Mean EQ-VAS ${ }_{\text {hypothetical }}$ & $74.15 \pm 22.83(111)$ & $81.64 \pm 19.14(98)$ & $83.60 \pm 14.68(45)$ & $84.32 \pm 12.70(41)$ & $79.49 \pm 19.70(295)$ \\
\hline Mean EQ-VAS ${ }_{\text {real }}$ & $74.91 \pm 19.02(114)$ & $81.78 \pm 16.88(101)$ & $83.47 \pm 13.90(45)$ & $84.10 \pm 11.26(41)$ & $79.75 \pm 17.07(301)$ \\
\hline
\end{tabular}

EQ-VAS ${ }_{\text {real }}$ refers to the parents' actual current HRQoL and EQ-VAS $S_{\text {hypothetical }}$ to their HRQoL in the hypothetical scenario in which care tasks would be taken over

Data expressed as mean \pm standard deviation $(n)$ or percentages $(n)$

In none of the groups, the differences in the means of both EQ-VAS scores were significant at the 0.05 level (paired-samples $t$ test)

Table 5 Parents who indicated a HRQoL change in the hypothetical scenario versus those who did not

\begin{tabular}{|c|c|c|c|c|}
\hline & $\begin{array}{l}\text { Group A } \\
\text { EQ-VAS }_{\text {hypothetical }}> \\
\text { EQ-VAS }_{\text {real }}(n)\end{array}$ & $\begin{array}{l}\text { Group B } \\
\text { EQ-VAS }_{\text {hypothetical }}= \\
\text { EQ-VAS }_{\text {real }}(n)\end{array}$ & $\begin{array}{l}\text { Group C } \\
\text { EQ-VAS }_{\text {hypothetical }}< \\
\text { EQ-VAS }_{\text {real }}(n)\end{array}$ & $P$ value $^{\mathrm{a}}$ \\
\hline $\begin{array}{l}\text { Difference EQ-VAS } \\
\text { (mean) }\end{array}$ & $11.2 \pm 8.5(47)^{\mathrm{b}, \mathrm{c}}$ & $0.0 \pm 0.0(222)^{\mathrm{b}, \mathrm{d}}$ & $-27.2 \pm 23.8(25)^{\mathrm{c}, \mathrm{d}}$ & $<0.001$ \\
\hline Anomaly (\% parents of ARM patients) & $79 \%(47)$ & $68 \%(222)$ & $84 \%(25)$ & 0.10 \\
\hline Sex (\% female parents) & $68 \%(47)^{\mathrm{b}}$ & $49 \%(222)^{\mathrm{b}}$ & $60 \%(25)$ & 0.04 \\
\hline Mean child's age & $5.3 \pm 3.4(47)$ & $6.4 \pm 2.9(222)^{\mathrm{d}}$ & $4.6 \pm 2.9(25)^{\mathrm{d}}$ & 0.002 \\
\hline Percentage parents taking care alone & $8.5 \%(47)$ & $5.0 \%(222)$ & $8.0 \%(25)$ & 0.56 \\
\hline Percentage parents that gave up paid work & $15 \%(46)^{\mathrm{b}}$ & $3 \%(215)^{\mathrm{b}}$ & $12 \%(24)$ & 0.001 \\
\hline No. of unpaid activities to spend less time on & $1.3 \pm 1.7(43)^{\mathrm{b}, \mathrm{c}}$ & $0.2 \pm 0.6(212)^{\mathrm{b}}$ & $0.6 \pm 1.1(22)^{\mathrm{c}}$ & $<0.001$ \\
\hline Mean monthly gross income $e^{\mathrm{e}}$ & $€ 2,857 \pm € 1,600(46)$ & $€ 2,996 \pm € 1,290(198)^{\mathrm{d}}$ & $€ 2,057 \pm € 1,047(23)^{\mathrm{d}}$ & 0.006 \\
\hline Mean symptom score $\mathrm{ARM}^{\mathrm{f}}$ & $9.0 \pm 3.1(37)^{\mathrm{b}}$ & $5.9 \pm 4.0(150)^{\mathrm{b}}$ & $6.7 \pm 3.2(21)$ & $<0.001$ \\
\hline Mean symptom score $\mathrm{CDH}^{\mathrm{f}}$ & $12.7 \pm 8.5(10)^{\mathrm{b}}$ & $6.3 \pm 6.3(72)^{\mathrm{b}}$ & $7.6 \pm 6.2(4)$ & 0.02 \\
\hline Mean EQ-VAS (parent form) ${ }^{\mathrm{f}}$ & $75.3 \pm 17.1(47)^{\mathrm{b}}$ & $86.2 \pm 13.4(219)^{\mathrm{b}}$ & $83.0 \pm 14.0(24)$ & $<0.001$ \\
\hline Mean difference EQ-VAS real and EQ-VAS ${ }_{\mathrm{gp}}$ & $-16.0 \pm 14.9(47)^{\mathrm{b}}$ & $-3.8 \pm 16.6(222)^{\mathrm{b}}$ & $-9.6 \pm 16.2(25)$ & $<0.001$ \\
\hline Mean difference EQ-5D and EQ-5D $\mathrm{gp}_{\mathrm{gp}}$ & $-0.08 \pm 0.15(46)^{\mathrm{b}}$ & $-0.01 \pm 0.16(222)^{\mathrm{b}}$ & $-0.10 \pm 0.25(22)$ & 0.003 \\
\hline
\end{tabular}

Data expressed as mean \pm standard deviation $(n)$ or percentages $(n)$

$G P$ general population

${ }^{\text {a }}$ One-way analysis of variance (ANOVA) (for continuous variables) or chi-square test (for categorical variables)

${ }^{\mathrm{b}}$ Difference between group A and group B significant at the 0.05 level (Bonferroni post hoc test or Yates' corrected chi-square test)

c Difference between group A and group C significant at the 0.05 level (Bonferroni post hoc test or Yates' corrected chi-square test)

d Difference between group B and group C significant at the 0.05 level (Bonferroni post hoc test or Yates' corrected chi-square test)

e Gross income from work was estimated on the basis of sex, age, and highest education [65]. Income from social security benefits or capital was not taken into account. For all children who have two caregivers with paid work, the incomes of both caregivers were considered

${ }^{f}$ While each parent (one or two) of a child had the opportunity to fill in a questionnaire on caregiving, the questions on symptoms and the EQ-VAS parent form were added only once and probably answered by one parent alone. Therefore, for some parents, this information might reflect their partner's opinion on their child's HRQoL

(Table 7). Generally, the directions of the coefficients met our expectations, although the residual variance was rather large. Apparently, the most important variables explaining HRQoL differences were type of anomaly (i.e., ARM or $\mathrm{CDH}$ ), symptom score, income, and the child's HRQoL as assessed on the EQ-VAS. In line with the hypothesis we made above, the differences between mothers and the general population could be explained better than those for fathers. For mothers, caregiving characteristics also better explained EQ-VAS differences than EQ-5D differences. 


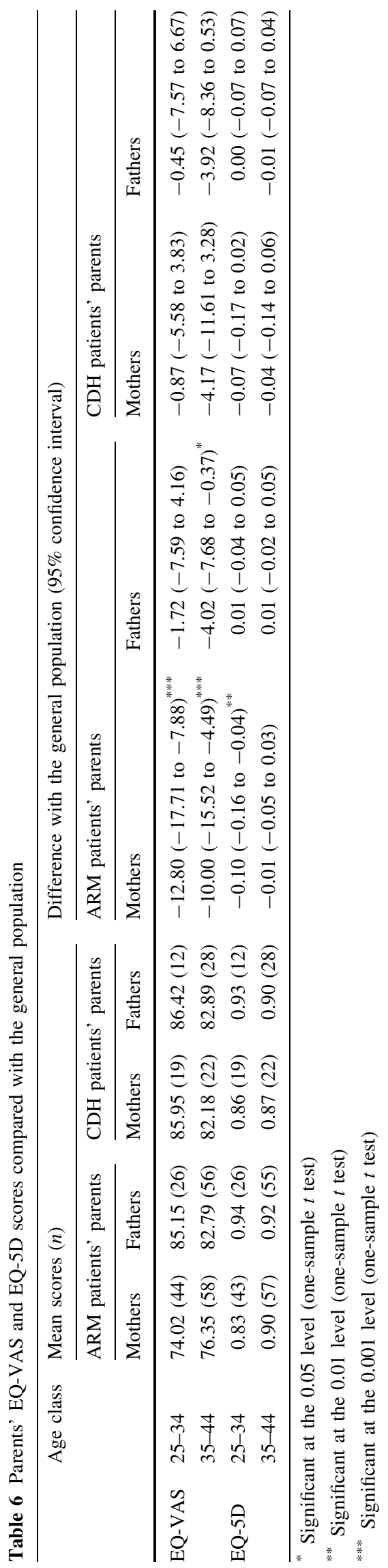

Finally, we estimated a restricted model, only including what seemed to be the most important independent variables (i.e., type of anomaly, symptom score, income, and the child's HRQoL). The Adjusted R Squares increased slightly (from $0.12,0.04,0.03$, and 0.03 (see Table 7) to $0.13,0.06,0.05$, and 0.05 , respectively).

\section{Discussion}

When adopting a societal perspective or a more narrow health care perspective in economic evaluations of health care interventions, the HRQoL effects in informal caregivers need to be taken into account. To date, few attempts to quantify these effects have been made. In this paper, we report on an evaluation done in a population of parents caring for children with major congenital anomalies, in an attempt to assess changes in caregivers' HRQoL specifically in relation to caregiving. Moreover, we investigated the impact of informal caregiving by comparing HRQoL of caregivers with that of the general population. Our findings emphasize the importance of investigating the position of informal caregivers when conducting economic evaluations and provide important lessons for the future.

Caregivers were shown to have a lower HRQoL than their counterparts in the general population. However, this result did not hold for some subgroups investigated, which implies that in this study, with the methods that we have used, effects on carers (either 'family effects' or 'caregiving effects') were not universal. In this respect, it should be noted that we included, where relevant, both parents of each child. They may not both be providing care (and thus experiencing the caregiver effect) to an equal extent, yet both parents may be expected to experience the family effect. The analysis might have shown stronger results if we had concentrated only on primary caregivers providing high levels of caregiving, thus experiencing both effects simultaneously. Besides, some parents may have come to perceive informal caregiving tasks as normal tasks and have difficulty to distinguish between their role as caregiver and a 'normal' parenting role. Furthermore, coping resources of the parents are likely to have affected the reported HRQoL [49, 50].

In view of these reflections, our findings suggest that the impact on primary caregivers may indeed be significant. Therefore, our study underlines the importance of considering caregivers, also in the context of economic evaluations. Moreover, it indicates that general HRQoL measures, as used in patients, may be able to detect HRQoL effects in caregivers. Using such outcome measures also facilitates the incorporation of HRQoL effects in common economic evaluations by, in principle, allowing the addition of HRQoL effects in caregivers to those in 
Table 7 HRQoL differences between parents and the general population explained

\begin{tabular}{|c|c|c|c|c|}
\hline \multirow{3}{*}{$\begin{array}{l}\text { Independent variables, standardized } \\
\text { regression coefficients (Bêta) }{ }^{\mathrm{a}}\end{array}$} & \multicolumn{4}{|l|}{ Dependent variable } \\
\hline & \multicolumn{2}{|l|}{ Mothers } & \multicolumn{2}{|l|}{ Fathers } \\
\hline & $\begin{array}{l}\text { Difference EQ-VAS } \\
\text { and EQ-VAS } \\
\text { gp }\end{array}$ & $\begin{array}{l}\text { Difference EQ-5D } \\
\text { and EQ-5D }{ }_{\mathrm{gp}}\end{array}$ & $\begin{array}{l}\text { Difference EQ-VAS } \\
\text { and EQ-VAS } \\
\text { gp }\end{array}$ & $\begin{array}{l}\text { Difference EQ-5D } \\
\text { and EQ-5D }{ }_{\mathrm{gp}}\end{array}$ \\
\hline (1) Congenital anomaly & $-0.21^{* *}$ & -0.01 & -0.05 & 0.02 \\
\hline (2) Child's age & -0.03 & 0.01 & -0.06 & 0.00 \\
\hline (3) ARM symptom score & -0.13 & -0.09 & -0.02 & -0.13 \\
\hline (4) $\mathrm{CDH}$ symptom score & 0.03 & -0.10 & -0.05 & $-0.18^{*}$ \\
\hline (5) Taking care alone or with a partner & 0.02 & -0.00 & -0.10 & -0.07 \\
\hline (6) Having given up paid work & 0.07 & 0.01 & 0.02 & 0.06 \\
\hline (7) Unpaid activities to spend less time on & -0.04 & -0.08 & 0.02 & -0.02 \\
\hline (8) Gross income & 0.11 & $0.20^{*}$ & 0.15 & 0.17 \\
\hline (9) Child's health-related quality of life & $0.28^{* *}$ & 0.08 & $0.24^{* *}$ & 0.04 \\
\hline Adjusted $\mathrm{R}^{2}$ & 0.12 & 0.04 & 0.03 & 0.03 \\
\hline
\end{tabular}

$G P$ general population

* Significant at the 0.05 level

** Significant at the 0.01 level

${ }^{a}$ Besides a constant. Forced entry method (tolerance: 0.0001)

patients. Analysts and policy makers should therefore be aware that if HRQoL improvement is an important aim, they should register HRQoL changes not only in patients but also in their caregivers and perhaps even in their broader social environment. This, in turn, may alter the cost-effectiveness of treatments, as was also discussed by Basu and Meltzer-who also called attention to possible equity concerns, in the sense that including effects on others (such as caregivers and family members) may lead to differences between patients who have or do not have a partner, for example [7].

In studies on the effects in caregivers, it should not be ignored that the results may partly depend on the setting. For example, in a parent-child relationship, caregiving is normal to some extent, although it diminishes with time, while this is less so in a partner relationship or a childparent relationship. Moreover, in the context of parents caring for their children, caregivers are typically relatively young, which may result in other effects on HRQoL (and well-being) than when caregivers are older. Furthermore, it is good to emphasize the broader social context of caregiving. For example, in a parent-child relationship, caregiving for one child may lead to the deprivation of other children in the family because of parental inattention or too much early responsibility [51, 52]. Finally, the decisions to provide care or to cease caregiving (or: 'the endogeneity of caregiving and health' [53]) will be made for different reasons in different settings, caused by different underlying mechanisms. Considering all this, an important area for future studies is to further unravel the influence of the relationship between caregiver and care receiver on the impact of caregiving. These issues have received little attention in the literature so far.

The EQ-5D was the instrument of choice in this study. Among its advantages are that it is a short, easily understandable questionnaire, and suitable for mail administration. Another advantage is that it includes all basic domains of HRQoL-psychological, physical, and social as well. So far, many studies have mainly focused on psychological health of caregivers. Studies of the physical health effects are less conclusive but suggest increased physical vulnerability [54-56]. Thus, it is desirable to adhere to a broadly defined HRQoL measure, without eliminating any domains in advance. Moreover, the EQ-5D, comprising the EQ-5D descriptive system and the EQ-VAS, has proven a reasonably valid instrument, also in people suffering from health problems that mainly affect specific dimensions of HRQoL [57-60]. The EQ-5D thus appeared an excellent starting point for attempting to quantify the HRQoL effects in caregivers. Nevertheless, more investigation into for example the sensitivity of different HRQoL instruments to these effects seems warranted. In that context, it is also important to note the social dimension of HRQoL. The EQ5D captures (elements of) this social dimension by asking about problems with performing usual activities, such as work, study, housework, family, or leisure activities. This can be an important problem for caregivers as well. This is also recognized in the CarerQol instrument [14, 15], which for example asks about the quality of the relationship with the patient and the support from one's social environment in providing care. Finally, it needs emphasizing that by concentrating on HRQoL effects other, broader quality- 
of-life effects on caregivers have remained unmeasured, though they likely exist $[8,14]$.

HRQoL effects in caregivers may be due to caregiving (the 'caregiving effect') and to the presence of illness within their social environment (the 'family effect'). To assess the exact magnitude of HRQoL changes specifically due to caregiving, we asked informal caregivers to express how their HRQoL would be if they would not have to provide informal care for their ill child anymore and compared this to their actual HRQoL. Several explanations for the fact that most people did not indicate a HRQoL change in the hypothetical scenario need to be considered:

(i) Responders may find it difficult to recognize that HRQoL problems are related to caregiving and to estimate how their HRQoL would be affected if they did not have to provide care tasks. Some people may find it difficult to comprehend such a hypothetical question, anyhow. Alternatively, there simply may be no significant effects on HRQoL (apart from 'family effects');

(ii) The fact that quite a number of parents (9\%) indicated that their HRQoL would decline in the hypothetical scenario could mean that the responders feel uncomfortable about the questions and give protest answers. Also, some parents may not want others (perhaps strangers) caring for their child's health. Furthermore, it may suggest positive process utility derived from caregiving, such as feelings of gratification, selfconfidence, and finding meaning in the care [61-63]. It is unclear to what extent this influences HRQoL, but one might argue that such a positive externality might be especially present in caring for one's child, although negative effects may still predominate.

(iii) The instrument appears to detect changes in HRQoL particularly in situations in which caregiving is very demanding, as shown by Table 5, which largely confirms our hypotheses on the combination of the two EQ-VAS scenarios. Only in these straining circumstances carers may actually experience HRQoL problems due to caregiving and be able and willing to report them.

These issues also seem to have played a role in two studies from the literature that took a similar approach to assessing HRQoL or well-being effects in carers [21, 64]. Even though there were differences with our study: Davidson and colleagues asked carers about their HRQoL under the assumption that the health of their relative was so good that he or she would not need care, while Brouwer et al. asked the caregivers to rate their happiness under the assumption that all caregiving tasks would be taken over.

In general, while our results appear to indicate that directly asking responders to estimate their HRQoL in the hypothetical scenario of not providing informal care may provide some relevant information such as revealing relatively strained caregivers, it also indicates that it is unlikely to provide exact measurements of the HRQoL effects of providing informal care. For the latter purpose, direct measurement of HRQoL (changes) and comparisons with relevant counterparts in the general population seem more appropriate.

Interestingly, there was a moderately strong correlation between the EQ-VAS scores of the caregivers themselves and the EQ-VAS scores of the child as indicated by the caregivers (e.g., for all female caregivers: $r=0.42$; $P<0.001)$. This provides an important indication for a health-related 'family effect', which is worth pursuing in future studies. Obviously, the close relationship between how the parent perceives his or her child feels and how the parent experiences his or her own HRQoL may also be due to concurrent effects on the parent's and the child's HRQoL (e.g., environmental and genetic influences) and to the fact that parents in being proxies for their children's HRQoL may have been influenced by their own HRQoL.

Future research may furthermore be aimed at better explaining the differences in terms of HRQoL between caregivers and the general population. It should be realized, for example, that even caring for a healthy child could disrupt HRQoL. Ideally, therefore, reference values are derived from parents with healthy children, not the general population. In this experiment using the EQ-5D, such data were not available. Moreover, HRQoL of non-caregiving parents or relatives of ill individuals could be measured as an alternative way to distinguish 'family effects' from 'caregiving effects' on HRQoL. Worthy of note are two other studies that attempted to separate these two types of effects. Bobinac et al. used regression techniques (taking an approach similar to our analysis presented in Table 7) to investigate to what extent the HRQoL or the well-being of caregivers can be explained by the patient's health (which would be indicative of the family effect) or the objective burden of caregiving (indicative of the caregiving effect) $[8,9]$. Finally, it would be interesting to see whether informative subjective burden measures would better explain HRQoL differences than the more objective explanatory variables used here. It must be noted, however, that this can induce problems of endogeneity in the analysis. In terms of studying the influence of coping and adaptation, one could register people's ability to cope and coping strategies to estimate the influence on HRQoL in relation to caregiving. Aspects of caregiving such as benefits of caring and the influence of support can be measured through the CarerQoL instrument and linked to well-being effects as well as HRQoL effects $[14,15]$.

To conclude, present understanding of HRQoL effects of informal caregiving is still rudimentary. In this paper, 
we tested a simple and straightforward method to measure the HRQoL impact in informal caregivers for use in economic evaluations of health care interventions. We also identified several issues that could usefully be addressed by future research. The demand for informal care and its impact on families are expected to rise, because several acute diseases have increasingly become chronic diseases (with long-term morbidity and a continuing need for care) and because of current trends toward early hospital discharge and outpatient treatment. These trends hold true for pediatrics as well as for other branches of medicine [24]. This makes it all the more important not to disregard the position of informal caregivers in future research efforts.

Acknowledgments We are indebted to M.A. Koopmanschap and F.F.H. Rutten for helpful suggestions and discussion during the preparation of this manuscript. This study was supported by the Swart-Van Essen Foundation and by grant 945-10-044 from the Netherlands Organisation for Health Research and Development (ZonMw), the Hague, the Netherlands.

Open Access This article is distributed under the terms of the Creative Commons Attribution Noncommercial License which permits any noncommercial use, distribution, and reproduction in any medium, provided the original author(s) and source are credited.

\section{References}

1. Drummond, M. F., Sculpher, M. J., Torrance, G. W., O’Brien, B. J., \& Stoddart, G. L. (2005). Methods for the economic evaluation of health care programmes (3rd ed.). New York: Oxford University Press.

2. Gold, M. R., Siegel, J. E., Russell, L. B., \& Weinstein, M. C. (Eds.). (1996). Cost-effectiveness in health and medicine. New York: Oxford University Press.

3. Brouwer, W. B. F., van Exel, N. J. A., Koopmanschap, M. A., \& Rutten, F. F. H. (1999). The valuation of informal care in economic appraisal. A consideration of individual choice and societal costs of time. International Journal of Technology Assessment in Health Care, 15(1), 147-160.

4. National Institute for Health and Clinical Excellence. (2006). Donepezil, galantamine, rivastigmine and memantine for the treatment of Alzheimer's disease. NICE technology appraisal guidance 111 (amended September 2007). London: National Institute for Health and Clinical Excellence.

5. van den Berg, B., Brouwer, W. B. F., \& Koopmanschap, M. A. (2004). Economic valuation of informal care. An overview of methods and applications. The European Journal of Health Economics, 5(1), 36-45.

6. Koopmanschap, M. A., van Exel, N. J. A., van den Berg, B., \& Brouwer, W. B. F. (2008). An overview of methods and applications to value informal care in economic evaluations of healthcare. PharmacoEconomics, 26(4), 269-280.

7. Basu, A., \& Meltzer, D. (2005). Implications of spillover effects within the family for medical cost-effectiveness analysis. Journal of Health Economics, 24(4), 751-773.

8. Bobinac, A., van Exel, N. J. A., Rutten, F. F. H., \& Brouwer, W. B. F. (2010). Caring for and caring about: disentangling the caregiver effect and the family effect. Journal of Health Economics, 29(4), 549-556.

9. Bobinac, A., van Exel, N. J. A., Rutten, F. F. H., \& Brouwer, W. B. F. (2011). Health effects in significant others: Separating family and care-giving effects. Medical Decision Making, 31(2), 292-298.

10. Brouwer, W. B. F., Tilford, J. M., \& van Exel, N. J. A. (2009). Incorporating caregiver and family effects in economic evaluations of child health. In W. Ungar (Ed.), Economic evaluation in child health. Oxford: Oxford University Press.

11. Baronet, A. M. (1999). Factors associated with caregiver burden in mental illness: a critical review of the research literature. Clinical Psychology Review, 19(7), 819-841.

12. Kinsella, G., Cooper, B., Picton, C., \& Murtagh, D. (1998). A review of the measurement of caregiver and family burden in palliative care. Journal of Palliative Care, 14(2), 37-45.

13. Vitaliano, P. P., Young, H. M., \& Russo, J. (1991). Burden: a review of measures used among caregivers of individuals with dementia. The Gerontologist, 31(1), 67-75.

14. Brouwer, W. B. F., van Exel, N. J. A., van Gorp, B., \& Redekop, W. K. (2006). The CarerQol instrument: a new instrument to measure care-related quality of life of informal caregivers for use in economic evaluations. Quality of Life Research, 15(6), $1005-1021$.

15. Al-Janabi, H., Flynn, T. N., \& Coast, J. (2010). Estimation of a preference-based carer experience scale. Medical Decision Making. doi:10.1177/0272989X10381280.

16. Beach, S. R., Schulz, R., Yee, J. L., \& Jackson, S. (2000). Negative and positive health effects of caring for a disabled spouse: Longitudinal findings from the caregiver health effects study. Psychology and Aging, 15(2), 259-271.

17. Roth, D. L., Perkins, M., Wadley, V. G., Temple, E. M., \& Haley, W. E. (2009). Family caregiving and emotional strain: associations with quality of life in a large national sample of middleaged and older adults. Quality of Life Research, 18(6), 679-688.

18. Schulz, R., \& Beach, S. R. (1999). Caregiving as a risk factor for mortality: The caregiver health effects study. Journal of the American Medical Association, 282(23), 2215-2219.

19. Mohide, E. A., Torrance, G. W., Streiner, D. L., Pringle, D. M., \& Gilbert, R. (1988). Measuring the wellbeing of family caregivers using the time trade-off technique. Journal of Clinical Epidemiology, 41(5), 475-482.

20. Dixon, S., Walker, M., \& Salek, S. (2006). Incorporating carer effects into economic evaluation. PharmacoEconomics, 24(1), 43-53.

21. Davidson, T., Krevers, B., \& Levin, L. A. (2008). In pursuit of QALY weights for relatives: empirical estimates in relatives caring for older people. The European Journal of Health Economics, 9(3), 285-292.

22. Basu, A., Dale, W., Elstein, A., \& Meltzer, D. (2010). A time tradeoff method for eliciting partner's quality of life due to patient's health states in prostate cancer. Medical Decision Making, 30(3), 355-365.

23. Arafa, M. A., Zaher, S. R., El-Dowaty, A. A., \& Moneeb, D. E. (2008). Quality of life among parents of children with heart disease. Health and Quality of Life Outcomes, 6, 91.

24. Hatzmann, J., Heymans, H. S. A., Ferrer-i-Carbonell, A., van Praag, B. M. S., \& Grootenhuis, M. A. (2008). Hidden consequences of success in pediatrics: Parental health-related quality of life-Results from the care project. Pediatrics, 122(5), e1030e1038.

25. Klassen, A. F., Klaassen, R., Dix, D., Pritchard, S., Yanofsky, R., O'Donnell, M., et al. (2008). Impact of caring for a child with cancer on parents' health-related quality of life. Journal of Clinical Oncology, 26(36), 5884-5889. 
26. Lawoko, S., \& Soares, J. J. F. (2003). Quality of life among parents of children with congenital heart disease, parents of children with other diseases and parents of healthy children. Quality of Life Research, 12(6), 655-666.

27. Poley, M. J., Stolk, E. A., Langemeijer, R. A. T. M., Molenaar, J. C., \& Busschbach, J. J. V. (2001). The cost-effectiveness of neonatal surgery and subsequent treatment for congenital anorectal malformations. Journal of Pediatric Surgery, 36(10), $1471-1478$.

28. Poley, M. J., Stolk, E. A., Tibboel, D., Molenaar, J. C., \& Busschbach, J. J. V. (2002). The cost-effectiveness of treatment for congenital diaphragmatic hernia. Journal of Pediatric Surgery, 37(9), 1245-1252.

29. Hamid, C. H., Holland, A. J. A., \& Martin, H. C. O. (2007). Long-term outcome of anorectal malformations: The patient perspective. Pediatric Surgery International, 23(2), 97-102.

30. Hartman, E. E., Oort, F. J., Sprangers, M. A. G., Hanneman, M. J. G., van Heurn, L. W. E., de Langen, Z. J., et al. (2008). Factors affecting quality of life of children and adolescents with anorectal malformations or Hirschsprung disease. Journal of Pediatric Gastroenterology and Nutrition, 47(4), 463-471.

31. Hashish, M. S., Dawoud, H. H., Hirschl, R. B., Bruch, S. W., El Batarny, A. M., Mychaliska, G. B., et al. (2010). Long-term functional outcome and quality of life in patients with high imperforate anus. Journal of Pediatric Surgery, 45(1), 224-230.

32. Ludman, L., \& Spitz, L. (1995). Psychosocial adjustment of children treated for anorectal anomalies. Journal of Pediatric Surgery, 30(3), 495-499.

33. Rintala, R., Mildh, L., \& Lindahl, H. (1994). Fecal continence and quality of life for adult patients with an operated high or intermediate anorectal malformation. Journal of Pediatric Surgery, 29(6), 777-780.

34. Desfrere, L., Jarreau, P. H., Dommergues, M., Brunhes, A., Hubert, P., Nihoul-Fekete, C., et al. (2000). Impact of delayed repair and elective high-frequency oscillatory ventilation on survival of antenatally diagnosed congenital diaphragmatic hernia: first application of these strategies in the more "severe" subgroup of antenatally diagnosed newborns. Intensive Care Medicine, 26(7), 934-941.

35. Kays, D. W., Langham, M. R., Ledbetter, D. J., \& Talbert, J. L. (1999). Detrimental effects of standard medical therapy in congenital diaphragmatic hernia. Annals of Surgery, 230(3), 340-351.

36. Gischler, S. J., van de Cammen-van Zijp, M. H. M., Mazer, P., Madern, G. C., Bax, N. M. A., de Jongste, J. C., et al. (2009). A prospective comparative evaluation of persistent respiratory morbidity in esophageal atresia and congenital diaphragmatic hernia survivors. Journal of Pediatric Surgery, 44(9), 1683-1690.

37. IJsselstijn, H., Tibboel, D., Hop, W. J. C., Molenaar, J. C., \& de Jongste, J. C. (1997). Long-term pulmonary sequelae in children with congenital diaphragmatic hernia. American Journal of Respiratory and Critical Care Medicine, 155(1), 174-180.

38. Nobuhara, K. K., Lund, D. P., Mitchell, J., Kharasch, V., \& Wilson, J. M. (1996). Long-term outlook for survivors of congenital diaphragmatic hernia. Clinics in Perinatology, 23(4), 873-887.

39. Koivusalo, A., Pakarinen, M., Vanamo, K., Lindahl, H., \& Rintala, R. J. (2005). Health-related quality of life in adults after repair of congenital diaphragmatic defects: a questionnaire study. Journal of Pediatric Surgery, 40(9), 1376-1381.

40. Peetsold, M. G., Huisman, J., Hofman, V. E., Heij, H. A., Raat, H., \& Gemke, R. J. (2009). Psychological outcome and quality of life in children born with congenital diaphragmatic hernia. Archives of Disease in Childhood, 94(11), 834-840.

41. Poley, M. J., Stolk, E. A., Tibboel, D., Molenaar, J. C., \& Busschbach, J. J. V. (2004). Short term and long term health related quality of life after congenital anorectal malformations and congenital diaphragmatic hernia. Archives of Disease in Childhood, 89(9), 836-841.

42. Brooks, R. (1996). EuroQol: the current state of play. Health Policy, 37(1), 53-72.

43. Kind, P., Hardman, G., \& Macran, S. (1999). UK population norms for EQ-5D. Discussion paper 172. York: University of York-Centre for Health Economics.

44. Dolan, P. (1997). Modeling valuations for EuroQol health states. Medical Care, 35(11), 1095-1108.

45. Luo, N., Johnson, J. A., \& Coons, S. J. (2010). Using instrumentdefined health state transitions to estimate minimally important differences for four preference-based health-related quality of life instruments. Medical Care, 48(4), 365-371.

46. Walters, S. J., \& Brazier, J. E. (2005). Comparison of the minimally important difference for two health state utility measures: EQ-5D and SF-6D. Quality of Life Research, 14(6), 1523-1532.

47. Pickard, A. S., Neary, M. P., \& Cella, D. (2007). Estimation of minimally important differences in EQ-5D utility and VAS scores in cancer. Health and Quality of Life Outcomes, 5, 70.

48. Portegijs, W., Boelens, A., \& Keuzenkamp, S. (2002). Emancipation Monitor 2002 [in Dutch]. The Hague: Social and Cultural Planning Office of the Netherlands, Statistics Netherlands.

49. Schulman, J. L. (1983). Coping with major disease: child, family, pediatrician. The Journal of Pediatrics, 102(6), 988-991.

50. Staab, D., Wenninger, K., Gebert, N., Rupprath, K., Bisson, S., Trettin, M., et al. (1998). Quality of life in patients with cystic fibrosis and their parents: What is important besides disease severity? Thorax, 53(9), 727-731.

51. Barlow, J. H., \& Ellard, D. R. (2006). The psychosocial wellbeing of children with chronic disease, their parents and siblings: An overview of the research evidence base. Child: Care, Health and Development, 32(1), 19-31.

52. Query, J. M., Reichelt, C., \& Christoferson, L. A. (1990). Living with chronic illness: a retrospective study of patients shunted for hydrocephalus and their families. Developmental Medicine and Child Neurology, 32(2), 119-128.

53. Coe, N. B., \& van Houtven, C. H. (2009). Caring for mom and neglecting yourself? The health effects of caring for an elderly parent. Health Economics, 18(9), 991-1010.

54. Brehaut, J. C., Kohen, D. E., Raina, P., Walter, S. D., Russell, D. J., Swinton, M., et al. (2004). The health of primary caregivers of children with cerebral palsy: How does it compare with that of other Canadian caregivers? Pediatrics, 114(2), e182-e191.

55. Tong, H. C., Kandala, G., Haig, A. J., Nelson, V. S., Yamakawa, K. S. J., \& Shin, K. Y. (2002). Physical functioning in female caregivers of children with physical disabilities compared with female caregivers of children with a chronic medical condition. Archives of Pediatrics and Adolescent Medicine, 156(11), 1138-1142.

56. Tong, H. C., Haig, A. J., Nelson, V. S., Yamakawa, K. S., Kandala, G., \& Shin, K. Y. (2003). Low back pain in adult female caregivers of children with physical disabilities. Archives of Pediatrics and Adolescent Medicine, 157(11), 1128-1133.

57. Coons, S. J., Rao, S., Keininger, D. L., \& Hays, R. D. (2000). A comparative review of generic quality-of-life instruments. PharmacoEconomics, 17(1), 13-35.

58. Essink-Bot, M. L., Krabbe, P. F. M., Bonsel, G. J., \& Aaronson, N. K. (1997). An empirical comparison of four generic health status measures. The Nottingham health profile, the medical outcomes study 36-item short-form health survey, the COOP/ WONCA charts, and the EuroQol instrument. Medical Care, $35(5), 522-537$.

59. Hollingworth, W., Mackenzie, R., Todd, C. J., \& Dixon, A. K. (1995). Measuring changes in quality of life following magnetic resonance imaging of the knee: SF-36, EuroQol or Rosser index? Quality of Life Research, 4(4), 325-334. 
60. Myers, C., \& Wilks, D. (1999). Comparison of Euroqol EQ-5D and SF-36 in patients with chronic fatigue syndrome. Quality of Life Research, 8(1-2), 9-16.

61. Cohen, C. A., Colantonio, A., \& Vernich, L. (2002). Positive aspects of caregiving: rounding out the caregiver experience. International Journal of Geriatric Psychiatry, 17(2), 184-188.

62. Lawton, M. P., Kleban, M. H., Moss, M., Rovine, M., \& Glicksman, A. (1989). Measuring caregiving appraisal. Journal of Gerontology, 44(3), P61-P71.
63. Motenko, A. K. (1989). The frustrations, gratifications, and wellbeing of dementia caregivers. The Gerontologist, 29(2), 166-172.

64. Brouwer, W. B. F., van Exel, N. J. A., van den Berg, B., van de Bos, G. A., \& Koopmanschap, M. A. (2005). Process utility from providing informal care: The benefit of caring. Health Policy, 74(1), 85-99.

65. Centraal Bureau voor de Statistiek. (2000). Werken en leren 2000-2001. Feiten en cijfers over de arbeidsmarkt en het onderwijs in Nederland. Samsom: Alphen aan den Rijn. 